\title{
Research on early grammatical gender processing: what do we know about Spanish-speaking children?*
}

\author{
Estudios sobre procesamiento temprano del \\ género gramatical: ¿qqué sabemos sobre los niños \\ hispanohablantes?
}

\author{
Anastasiia Ogneva \\ Universidad de A Coruña, Facultad \\ de Ciencias de la Educación, \\ Departamento de Psicología \\ anastasiia.ogneva@udc.es
}




\section{Abstract}

This paper reviews recent research on grammatical gender acquisition and processing by speakers of Spanish. We consider studies on monolingual, bilingual, heritage speakers, and children diagnosed with Developmental Language Disorder (DLD). The main focus of this article is to review research on how Spanish-speaking toddlers process grammatical gender information during sentence comprehension. According to the results of the reviewed research, the course of gender acquisition in DLD children seems to differ from typically developing monolingual children. Furthermore, from early on typically developing Spanish-speaking are sensitive to distributional co-occurrences of gender, i.e., gender information embedded in the determiners and adjectives. The review also includes studies on grammatical gender processing by adults that have shown a facilitation effect of transparent gender on noun recognition.

Keywords: language acquisition; language processing; grammatical gender acquisition; gender cues; Spanish

\section{Resumen}

Este artículo reseña estudios recientes sobre adquisición y procesamiento del género gramatical en la población hispanohablante. Se comentan estudios con hablantes monolingües, bilingües, hablantes de herencia y niños diagnosticados con el Trastorno Evolutivo del Lenguaje (TEL). El enfoque principal es la revisión de estudios centrados en el procesamiento del género gramatical durante la comprensión de oraciones por parte de niños hispanohablantes. Según los resultados de dichas investigaciones, la adquisición del género gramatical parece ser diferente entre niños con TEL y aquellos con desarrollo típico. Además, desde edades tempranas, los niños hispanohablantes con desarrollo típico muestran sensibilidad a las "coocurrencias distribucionales de género", es decir, a la información sobre el género gramatical que proporcionan los determinantes y artículos. Asimismo, se incluyen estudios sobre el procesamiento del género gramatical por parte de adultos, que muestran el efecto facilitador del género transparente durante el reconocimiento de nombres.

\section{Palabras clave: adquisición del} lenguaje; procesamiento del lenguaje; adquisición de género gramatical; claves del género; español 


\section{Introduction}

Grammatical gender, being a part of language acquisition in children, has attracted interest of linguists and developmental psychologists over decades. Children acquiring languages with grammatical gender (e.g., Spanish, French, Russian) have to learn gender categorization of nouns and the way to assign gender to the new words they learn. In addition to learning the gender feature of nouns, children also need to understand the gender agreement rules. In Spanish, nouns are either feminine or masculine. Both genders present typical morphophonological cues (- $a$ ending to denote feminine, $-o$ ending to denote masculine), which are also applicable for plural forms (e.g., chic- $a(s)$ ' $\operatorname{girl}(\mathrm{s})$ ', chic-o(s) 'boy(s)'). While the $-a$ and $-o$ endings have high cue reliability and availability among nouns, the gender of nouns ending in $-e$ or in a consonant cannot be predicted from the word form alone. Besides, there is a small number of nouns where gender-ending agreement is reversed (feminine nouns that end in -o, e.g., man-o, 'hand' and masculine nouns that end in - a, e.g., sofá, 'sofa'). Thus, these nouns provide misleading cues for gender assignment and agreement.

Although gender marking and agreement are complex processes, developmental studies have suggested that grammatical gender is acquired at about 3 years of age across several languages. Traditional approaches have mainly focused on the production of utterances containing grammatical gender or longitudinal observations of grammatical gender acquisition by children (Barreña, 1997; Clark, 1985; Hernández-Pina, 1984; Pérez Pereira, 1991).

\footnotetext{
This study has been financed by the following institutions: The Regional Government of Galicia (Consellería de Cultura, Educación e Ordenación Universitaria da Xunta de Galicia, grant ED481A-2017/279) and the Universidade da Coruña (UDC) International Doctoral School and INDITEX (Escola Internacinal de Doutoramento e INDITEX SA, three-month research stay grant). I would also like to thank two anonymous reviewers whose comments have improved this paper.
} 
These studies show that children do not make agreement errors or omissions of the gendered articles they produce.

A general trend in language acquisition considers that comprehension precedes production. In fact, studies on early child language suggest that children understand more than they can produce initially (Clark \& Hecht, 1983). Clark and Hecht mention that this is usually observed in many classic diary studies, and experimental research (Huttenlocher, 1974; Rescorla, 1980 in Clark \& Hecht, 1983). In fact, Clark (1993: 246) formulates the following premise:

Logically, comprehension must precede production. How else can speakers know which words to use to convey a particular meaning? They must already have mapped the relevant meanings onto specific forms, and have these units represented in memory, to be accessed on subsequent occasions whenever they hear the relevant forms from others.

Modern technological advances have made it possible to gain insights on early language comprehension when utterances produced by children are limited or when children are yet to pronounce their first words. Thus, language processing is understood as a process of how language (e.g., word meaning, sentence meaning, etc.) is computed and represented in the brain. Early gender processing has been studied in several languages, such as French (Van Heugten \& Shi, 2009), Dutch (Van Heugten \& Johnson, 2011), or Czech (Smolík \& Bláhová, 2019). It has been confirmed that very young children (22-36 months old) start to acquire grammatical gender from early language development stages, even before producing fully grammatical utterances.

This paper reviews the current research on early grammatical gender processing in Spanish-speaking children, i.e., what young toddlers comprehend about grammatical gender before producing it. Section 2 outlines an overview of the grammatical gender system in Spanish, as well as the cues used by native speakers to predict grammatical gender and assign it to new words. Sec- 
tion 3 describes studies that focus on gender processing in Spanish-speaking monolingual and bilingual adult speakers. Section 4 reviews studies on early gender processing in Spanish-speaking toddlers and provides evidence from empirical studies. Finally, Section 5 highlights concluding remarks and proposes lines for future research.

\section{On grammatical gender in Spanish}

Spanish belongs to the group of languages with a two-way gender system. ${ }^{1}$ All Spanish nouns are either masculine or feminine (Corbett, 1991; Harris, 1991). Animate nouns (those that denote people and animals) are classified on the basis of biological sex. Therefore, nouns like tio/tía 'uncle/aunt' or gato/gata 'cat-M/F'2 would belong to masculine or feminine groups as their referents are either males or females.

However, a number of animate nouns sometimes involve cue mismatches, i.e., a morphologically masculine noun refers to a female referent, for example, mano (hand). Thus, establishing the gender agreement with such nouns is usually tricky in early development stages (Ogneva, 2020).

As for inanimate nouns, although the classification is deemed arbitrary, the morphophonological characteristics of nouns are useful to denote gender. Generally, inanimate nouns ending in -o (e.g., verano, 'summer-M') are masculine, whereas those ending in - $a$ (e.g., ventana 'window-F') are feminine (Harris, 1991). These nouns are considered to be phonologically marked or transparent. Nouns that end in a consonant, $-e$, or vowels other than $-a$ and $-o$ are called opaque, as they may either be masculine (e.g., puente, 'bridge-M';

1 It is worth highlighting that a neuter gender is adequate when abstract adjectives are used nominally, e.g., lo bueno (the good one). In this case, lo is not considered to be a determiner but a pronoun.

2 Hereafter, nouns that are masculine or feminine in Spanish are marked with "M" or "F". 
sillón, 'arm-chair-M') or feminine (e.g., fuente, 'fountain-F'; razón, 'reason-F'). Besides opaque nouns, there are multiple exceptions to the "masculine $-o$ / feminine $-a$ " rule. As mentioned before, the noun mano (hand), although being feminine, ends in - $o$. In fact, some research showed that this gender-ending inconsistency may give rise to agreement errors such as mota rota instead of moto rota (broken motorcycle) (Hernández-Pina, 1984).

Some studies also explored the frequencies of specific endings and the associated gender. For instance, Bull (1965) concluded that nouns ending in $-l,-r,-n$, and $-s$ would be masculine in $96 \%$ of cases, whereas those ending in - $d$, -ción, -sis, or -it would be feminine in $98 \%$ of words. So, although phonological regularities are useful to determine the grammatical gender of a noun, they are not $100 \%$ reliable (Arias Trejo, Falcón \& Alva, 2013).

Gender requires agreement between a noun and its determiners. In Spanish, both indefinite and definite articles preceded the noun, whereas adjectives usually follow it. Thus, nouns preceded by the definite article la or the indefinite article una are feminine, whereas nouns preceded by the definite article $e l$ or the indefinite article un are masculine. As previously suggested by Arias Trejo et al. (2013), for feminine nouns the combination of gender-marked determiner la or una and ending in - $a$ would act as an accelerator to access the grammatical gender information. For opaque nouns such as balón 'ball', the preceding article in some cases can be the only gender information available: el balón 'the-m ball'. However, extracting gender information from the determiner alone can also lead to agreement errors. When the beginning of a Spanish feminine noun is a stressed $/ a /$, the definite determiner $l a$ and determiners ending in - a (una, 'a-F'; alguna, 'some-F'; ninguna, 'none-F') have to be changed to the masculine form in order to avoid pronouncing a double /a/. A study by Eddington and Hualde (2008) reported that native speakers are sometimes confused by this variation and make mistakes related to the preceding prenominal modifier, for instance, mucho hambre 'much-M hunger-F' instead of mucha hambre 'much-F hunger-F'. 
To conclude, in Spanish there are three possible indicators that help to extract gender information: i) syntactic, coming from the gender agreement between a noun and its determiner, ii) phonological, embedded in the ending of a noun, and iii) semantic, revealed from the biological sex of the referent (Pérez Pereira, 1991). As previously suggested, grammatical gender cannot be reliably retrieved from a single source of information. In some cases, there are no cues that allow extracting gender; for instance, dos árboles verdes 'two green trees' is a masculine noun phrase, whereas dos calles grandes 'two big streets' is a feminine one. Then, as also reported in previous studies, gender information is more easily retrieved and processed when several cues are available (Pérez Pereira, 1991; Arias Trejo et al., 2013). As Grüter, Lew-Williams and Fernald (2012: 193) suggest, "the only consistent and fully reliable cue to a noun's gender class is distributional, consisting of its co-occurrence relations with transparently gender-marked modifiers, such as determiners and (attributive and predicative) adjectives".

\section{Gender processing studies in adults}

Grammatical gender processing has recently received increasing attention from psycholinguistic researchers. Generally, the discussion is focused on the issue of how the linguistic system determines the gender of a noun. One group of researchers (Miozzo \& Caramazza, 1997; Levelt, Roelofs \& Meyer, 1999) claim that gender information is retrieved via the lexical route. According to this view, native speakers store nouns associated with a given gender in their mental lexicon. Thus, when a speaker needs to access gender information, e.g., in sentence comprehension, the gender is extracted via lexical activation. Nonetheless, as seen in Section 2, Spanish gender is strongly correlated with formal features of nouns. For this reason, some authors argue that the cognitive system takes advantage of this source of information (Caffarra \& Barber, 2015). This idea is in line with the hypothesis of Gollan and Frost (2001). 
According to this view, besides the lexical route of gender retrieval, there is a second route based on the formal features of words. Accordingly, the gender of two Spanish words, e.g., ventana 'window-F' and sartén 'frying pan-F', can be extracted in two different ways. In the case of ventana, a gender-marked ending is available, so the system can either extract gender-accessing lexical information (lexical route), or it can extract this information from the feminine ending - $a$ (form-based route). However, in the case of sartén, only the lexical route of gender retrieval is available.

Electroencephalogram (EEG) studies on Spanish speakers found evidence of two routes of gender assignment (Caffarra, Janssen \& Barber, 2014; Caffarra \& Barber, 2015). Caffarra et al. (2014) investigated gender agreement processing using a grammaticality judgement task. In this study, the authors used Spanish article-noun pairs with or without gender agreement, e.g., el queso 'the-M cheese-M' or la queso 'the-F cheese-M' in a transparent condition, and el reloj 'the-M watch-M' or la reloj 'the-F watch-M' for an opaque condition. The results revealed that transparent and opaque nouns are processed differently, as different event-related potential (ERP) signals emerged. They have also found a higher accuracy for transparent vs. opaque nouns, which lead to the conclusion that gender transparency facilitates noun recognition. Similar results were obtained in a study with Portuguese-speaking adults, which revealed that gender errors are more easily detected between a transparent noun and a determiner than between an opaque noun and its determiner (Alencar de Resende, Mota \& Seuren, 2018).

Based on previous studies conducted on isolated words or word pairs, Caffarra and Barber (2015) tested the sensitivity of the system to formal gender cues in sentence comprehension. Their findings suggest that the system can detect formal gender cues at an early stage; according to the authors, this probably plays a role in the word recognition process. Both findings are consistent with behavioural studies conducted with Italian speakers (Bates, Devescovi, Pizzamiglio, D’amico \& Hernández, 1995; Bates, Devescovi, 
Hernández \& Pizzamiglio, 1996; Caffarra, Siyanova-Chanturia, Pesciarelli, Vespignani \& Cacciari, 2015).

Important insights on gender processing have been provided by studies with L2 learners and bilingual speakers. Findings from these studies have shown that even advanced and near-native L2 learners have difficulties with Spanish gender assignment (White, Valenzuela, Kozlowska-MacGregor \& Leung Yan-Kit, 2004; Montrul, Foote \& Perpiñán, 2008; Alarcón, 2009; Lew-Williams \& Fernald, 2010; Alarcón, 2011; Sagarra \& Herschensohn, 2011; Grüter, Lew-Williams \& Fernald, 2012). A study by Montrul, Davidson, De la Fuente \& Foote (2014) explored how the age of acquisition of Spanish affects gender processing of canonical and non-canonical noun endings, comparing native speakers of Spanish, L2 students, and heritage speakers. They found that canonicity largely affects both the L2 group and heritage speakers, suggesting that reduced language use and input frequency affect the retrieval of non-canonical or opaque ending nouns from memory. Alarcón (2009) explored reaction times (RT) in gender agreement processing during an online comprehension task among native speakers of Spanish and L2 Spanish learners. Different linguistic variables were compared, such as the noun class (semantic or non-semantic, e.g., vecino, 'neighbor', and servicio, 'service'), gender (masculine or feminine), transparency (overt or non-overt), and agreement between noun class and gender (match or mismatch). The results obtained in this study indicate that both native speakers and L2 learners are faster with semantic nouns. Furthermore, a transparency effect on RTs was found for native speakers only. However, Alarcón (2006) previously found that L2 learners were significantly more accurate with overt- than non-overt-ending nouns.

Lew-William and Fernald (2010) replicated their study with Spanish-speaking toddlers (Lew-Williams \& Fernald, 2007) on L2 intermediate learners. Their results showed that native speakers use determiners as an informative cue to gender, whereas L2 learners do not. Grüter, Lew-Williams, and Fernald (2012) repeated this study with advanced L2 learners. Evidence from this study 
suggests that advanced L2 learners exhibit a weaker use of gendered articles as facilitators during online comprehension tasks.

In conclusion, the studies mentioned above have provided evidence that native speakers of Spanish are sensitive to gender information embedded in the formal features of nouns, specifically, $-o /-a$ endings. The results of these studies also report that transparent and opaque nouns are processed differently, supporting the theory of two routes of gender processing. L2 learners and heritage speakers seem to be sensitive to gender cues, albeit not to the same extent as native speakers.

\section{Early gender processing studies}

Generally, research studies on gender acquisition have questioned whether children begin assigning gender by using grammar (morphosyntactic cues) or by paying attention to extralinguistic information (biological sex). Evidence from longitudinal and experimental studies focused on gender acquisition reports that gender is acquired early, at approximately 3-4 years of age (Hernández-Pina, 1984; Pérez Pereira, 1991; López, Fernández, Gallo \& Mariscal, 1994). In fact, the distinction of biological sex between males and females (e.g., niño/niña 'boy/girl') appears in speech development in toddlers before the second birthday (Hernández-Pina, 1984). Psycholinguistic research provides convincing evidence that Spanish-speaking children use morphosyntactic cues to assign gender to novel nouns. Interestingly, semantic cues do not seem to be used as potential sources of gender information by children (Pérez Pereira, 1991, Pérez-Tattam et al., 2019).

\subsection{Studies based on production}

Before comprehension studies became available, researchers focused on the production of grammatical gender in children. Previous research with French- and Spanish-speaking children (Karmiloff-Smith, 1979; Pérez Pereira, 1991; Boloh \& Ibernon, 2010; 
Pérez-Tattam, Ezeizabarrena, Stadthagen-González \& Mueller, 2019) claim that grammatical gender is acquired approximately at 4 years of age. In fact, it was shown that children pay attention to different linguistic clues when assigning gender to novel nouns.

Considering production-based studies in Spanish-speaking children, Pérez Pereira (1991) conducted a study in 160 children aged 4-11 to identify the linguistic cues used by children when assigning a grammatical gender to novel nouns. Experimental items were designed according to the following criteria:

1) A single cue available (e.g., phonological, as in dos carepos).

2) Two cues in agreement (e.g., syntactic and phonological, as in una lodena).

3) Two cues in conflict (e.g., syntactic and phonological, as in un satila).

Children were presented with pictures of fantasy animals with an instruction (mira, este dibujo es una lodena 'look, this picture is a-F lodena-F'). Afterwards, they were shown a picture of the same animal but painted in a different color, and were asked what they saw in this picture. Children were expected to say an adjective in agreement with the noun gender, e.g., es una lodena roja 'it is a red-F lodena-F'. The results of this study indicate that the semantic cue is not taken into account by Spanish-speaking children, since they mostly used a phonological or syntactic cue when establishing the noun-adjective agreement.

A recent production-based study by Pérez-Tattam et al. (2019) with Spanish-speaking and Spanish-Basque bilinguals aged 5-6 years used same-core nonce words, such as nolet-o, nolet- $a$, nolet-e (one within a masculine context and one within a feminine context). These words were presented in different conditions:

1) No linguistic cue, e.g. vamos a ver tres noletes 'we will see three noletes'. 
2) One cue, e.g. vamos a ver tres noletes simpáticas 'we will see three lovely-F noletes'.

3) Two cues, e.g., vamos a ver a unas noletes simpáticas 'we will see some-F lovely-F noletes'.

The results of this study have shown a clear preference for the masculine gender in both groups of children ( $83 \%$ in bilingual children and $64 \%$ in monolingual children). When children assigned a grammatical gender based on a masculine or feminine context, in the former, the masculine gender was preferred in $74 \%$ of the cases, whereas in the latter, the feminine gender was chosen in only $39 \%$ of the answers. It is concluded that morphological cues are more important than semantic ones. A masculine overgeneralization of determiners and clitics was also reported by Martínez (2018) for young typically developing monolingual Spanish-speaking children and young heritage speakers.

Other production studies have investigated gender acquisition in clinical contexts. Specifically, researchers have focused on children diagnosed with Developmental Language Disorder (DLD) and how they acquire grammatical gender. ${ }^{3}$ DLD children are reported to show deficits related to multiple linguistic features, especially grammar (Leonard, 2014). Thus, grammatical gender and gender agreement have been topics of interest in psycholinguistic research. Some studies suggested that DLD children face difficulties in gender assignment and agreement. For example, Bosch and Serra (1997) reported omissions of definite articles in spontaneous speech in 12-year-old DLD children. Bedore and Leonard $(2001,2005)$ explored the use of definite and indefinite articles in DLD children, comparing them to typically developing children. The results of these studies indicate that DLD children omit both types of articles more frequently than typically developing children. Similar results were obtained by Anderson and Souto (2005),

3 For a full review on grammatical gender acquisition by DLD children in Spanish see Ogneva (2023). 
who explored the spontaneous speech of DLD children. Several experiments showed that these children omit feminine and masculine determiners (Bedore and Leonard, 2001, 2005; Jacobson \& Schwartz, 2002; Jackson Maldonado and Maldonado, 2017). Clitic pronouns were also reported to cause difficulties in DLD children, such as gender agreement in clitics, omissions, difficulties in the production of clitics, etc.

Anderson and Lockowitz (2009) investigated whether DLD children are sensitive to gender cues embedded in nouns. The authors used an elicited production task, where children watched a picture of a new object and listened to a sentence naming it. Experimental items were grouped according to the presence of a given gender cue (noun ending, article cue, adjective cue, or semantic transparency). The results of this study revealed differences in accuracy as rated for items with article and adjective cues, indicating that DLD children show limitations in gender agreement between nouns and articles or adjectives, and difficulties in using the gender cues available in noun determiners and modifiers.

To summarize, production-based studies indicate that typically developing Spanish-speaking children acquire grammatical gender quite early, before the age of four. Previous studies suggest that masculine gender is either dominated earlier than feminine gender or used by default. Research with DLD children has shown limitations in the use of grammatical gender, such as article omissions and gender agreement errors.

\subsection{Studies based on comprehension}

The previous section, mentioned studies on gender processing in adults. We will now address how children access and retrieve gender information. Previous studies conducted with French and Dutch learners indicate that children who acquired French (25 months old) were able to retrieve gender information from the determiners in an object recognition task (Van Heugten \& Shi, 2009). Essentially, children identified the object more efficiently when present- 
ed with two objects of different gender. In a similar task, Dutch learners were not efficient at recognising target nouns (Van Heugten \& Johnson, 2011). These results, as stated by Arias Trejo et al. (2013), may be explained by the transparency of the system: the Dutch language includes two determiners (common and neuter) for three genders (masculine, feminine, and neuter), whereas French contains two determiners for two genders. Considering that Spanish has a transparent-gender system, the projection is that children would be able to retrieve gender and use this information in an object recognition task.

Research focused on early gender processing by Spanish-speaking children is scarce. To our knowledge, three studies have been carried out and published to date. Lew-Williams and Fernald (2007) conducted a study with 34-42-month-old Spanish toddlers. Children were tested in an eye-tracking procedure. They were presented with a pair of pictures of either the same (la pelota, 'the-F ball-F'; la galleta, 'the-F cookie-F') or different grammatical gender (la pelota, 'the-F ball-F'; el zapato, 'the-M shoe-M') (see Figure 1). At the same time, children heard an audio stimulus mentioning one of these pictures, for example, encuentra la galleta 'find the cookie'.

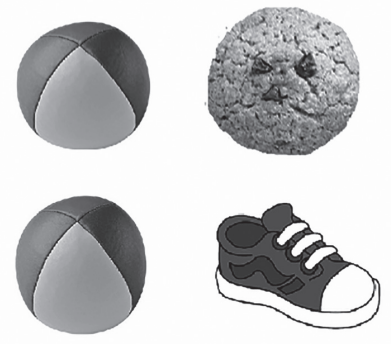

Figure 1. Examples of visual stimuli used in the experiment of Lew-Williams and Fernald (2007). The two objects depicted at the top are same-gender items, whereas the objects at the bottom are different-gender items

Lew-Williams and Fernald (2007) conducted a research with 34-42-month-old Spanish toddlers. Children and adult controls 
were tested in an eye-tracking procedure. Figure 2 shows the time course of finding the target-object for adults and toddlers. The curves represent changes in the mean proportion across trials when participants looked at the correct picture, across 33-ms intervals measured from the article onset (Lew-Williams \& Fernald, 2007: 4). These results suggest that, although children were slower and less accurate than adults, both groups of participants responded faster on different-gender trials than on same-gender trials. Specifically, 2-3-year-old Spanish learners can identify common nouns 90 milliseconds faster (time elapsed from the beginning of the trial) when a determiner provides a cue about the grammatical gender of the referent.

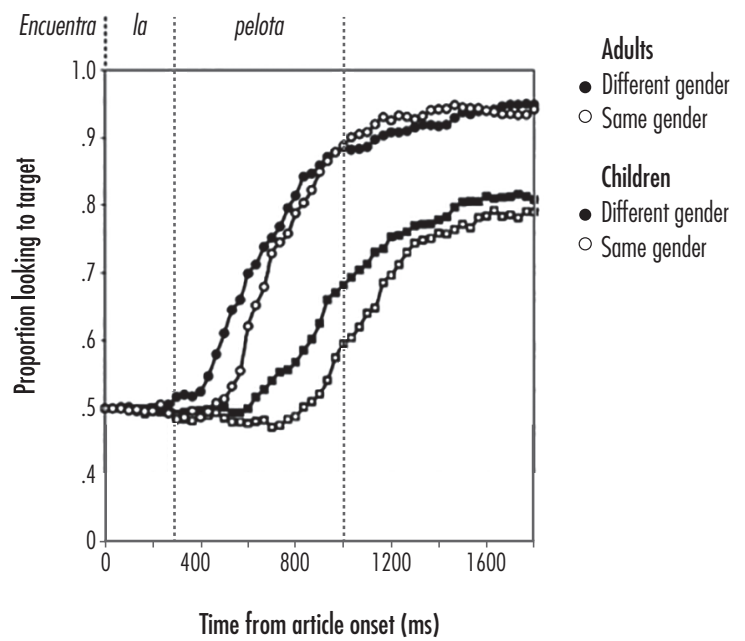

Figure 2. The time course looking to same-gender or different-gender items by children and adults in Lew-Williams \& Fernald (2007). The curves show changes in the proportion of looking to the picture, measured from the article onset

From a critical perspective, this study has two mayor shortcomings. The authors did not include opaque nouns in their experiment. Hence, the study did not address whether children are able 
to process the gender of these words. As a result, this study provides no evidence on the facilitation effect of transparent nouns, as reported for adults (Caffarra et al., 2014). The second limitation of this study is that only common words were used, so it does not show how children extract gender information about previously unknown nouns.

The pilot study by Lew-Williams and Fernald (2007) was extended by Arias Trejo et al. (2013). Specifically, these authors tested the ability of children to use determiners with non-transparent words, including opaque nouns such as pie 'foot', llave 'key', and calcetin 'sock'. The participants in this study were grouped according to age: 24 months old, 30 months old, and 36 months old. In two experiments, children were presented with pairs of common objects (a target and a distractor) and listened to a feminine or masculine definite or indefinite article. For example, as shown in Figure 3, children watched an apple (manzana-F) and a banana (plátano-M) and listened to "Mira" (200 ms after the start of display of the visual stimuli), followed by either la or el (between $2000 \mathrm{~ms}$ and $4000 \mathrm{~ms}$ post-start). Finally, children listened to the target label (e.g., manzana) $2000 \mathrm{~ms}$ to $4000 \mathrm{~ms}$ post-start.

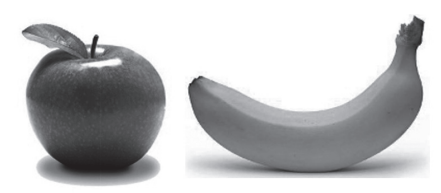

Figure 3. Examples of visual stimuli used in Arias Trejo et al. (2013)

The results from both experiments show that toddlers were able to use definite and indefinite articles to find the target object. Interestingly, 24-month-old children used the indefinite articles un and una, but not the definite articles $\mathrm{el}$ and $l a$, whereas older toddlers (30-36 months old) were able to use both types of articles to correctly infer a target. This result suggests that the ability to use indefinite articles emerges earlier than the use of definite articles. The novelty 
of this work, as mentioned above, consisted in that the researchers included irregular nouns in their experiment. To conclude, this study shows that children are sensitive to the article-noun agreement. In early development stages (24 months of age), toddlers seem to rely on morphophonological patterns, but later (approximately at 3 years old), toddlers are able to use syntactic information when the ending of a noun is not available.

The results of this study, particularly the fact that younger toddlers (24 months old) were not able to use the definite articles $e l$ and $l a$, may be questioned in light of existing longitudinal evidence. Hernández-Pina (1984) suggested that definite articles are acquired earlier in child speech, but indefinite articles are used more frequently. Further research is needed to examine this aspect.

Arias Trejo and Alva (2012) have also reported that Spanish-speaking toddlers, besides using gender information embedded in articles, benefit from the morphological agreement of adjectives. They included 30-month-old children in an intermodal preferential looking exercise. As Figure 4 shows, two unfamiliar objects were displayed in the experiment: a diabolo and a fire hydrant. There were eight variants of each image: red, yellow, broken, pretty, small, blue, green, and big. The first five variants were used during the training, whereas the remaining three were used during the test. As for the auditory stimuli, the authors used a novel masculine noun pileco and a novel feminine noun betusa. During the training, toddlers watched eight trials in which both objects (the hydrant and the diabolo) were presented individually; a characteristic of the object changed each time. For example, for the yellow hydrant, toddlers heard "Mira, es amarillo" 'look, it is yellow' and subsequently "Mira, es bonito" 'look, it is pretty'. After this training, children were presented with two objects simultaneously and listened, in a random sequence, "mira, una betusa" 'look, a-F betusa' and "mira, un pileco" 'look, a-M pileco'.

Fifty percent of the toddlers were trained as follows: masculine adjectives for the hydrant and feminine adjectives with the diabolo, and the remaining $50 \%$ of the children were trained with the 
opposite pattern: masculine adjectives for the diabolo and feminine adjective for the hydrant. Each trial lasted 5,000 milliseconds, as shown in Figure 4. The test trials were split into two phases: a pre-naming and a post-naming phase. The first served to measure a baseline image preference, whereas the post-naming phase served to confirm that toddlers associate a novel noun with the correct object.

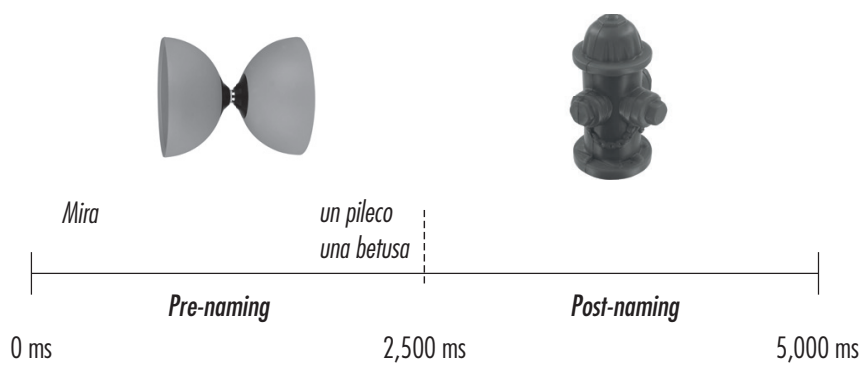

Figure 4. Example of a test trial used in Arias Trejo \& Alva (2012)

The results of the above study revealed that Spanish 30-month-old toddlers were able to identify the correct target referent in the test, on the basis of an $-o /-a$ pattern established for common adjectives during the training phase. Specifically, when children listened to adjectives ending in $-a$, such as amarilla, roja, rota, they exhibited preference for the target object called betusa, whereas preference to associate the nonce-word pileco was observed for the item previously described with masculine adjectives such as amarillo, rojo, roto. This study provided evidence that 30-month-old Spanish toddlers are capable of using grammatical gender information contained in adjectives. Another key finding highlighted by researchers is that children are highly sensitive to adult speech. In Spanish, a referent name is commonly replaced by a gendered pronoun (e.g., pásamela, 'pass it-F to me', when referring to a ball-F (pelota)) or to describe an object instead of naming it (e.g., la blanca 'the white-F one'), as mentioned by Arias Trejo and Alva (2012: 6), children are frequently exposed to expressions like mira, está rota 'look, it is 
broken-F'. Thus, the data provided by this experiment showed that children can bootstrap meanings from the morphological cues provided by an adjective. The outcomes of this research, however, need to be replicated with younger Spanish-speaking toddlers to explore whether there is a similar effect on them as well. In a recent study conducted by Smolík and Bláhová (2019), Czech 21-24-monthold toddlers participated in trials using a similar paradigm. Czech is a language with a rich morphology and no mandatory articles preceding a noun, so the authors used adjectives in the trial. The results suggest that some children were able to extract gender information from the bound morphemes included in the adjective. This leads to the conclusion that even at the two-word combination stage, children are already aware of the basic properties of their native language.

\section{Overall conclusion and future directions of research}

This paper reviewed studies addressing early gender processing in Spanish-speaking toddlers. Research with native speakers of Spanish has shown that adults are sensitive to gender cues, specifically the ending of nouns, which help them to identify exceptions to noun-article gender agreement (Caffarra et al., 2014), and process gender information within sentence comprehension (Caffarra \& Barber, 2015).

Regarding early gender processing, studies conducted with Spanish-speaking toddlers report that children are able to use both articles and adjectives to predict the upcoming nouns in a sentence (Lew-Williams \& Fernald, 2007; Arias Trejo \& Alva, 2012; Arias Trejo et al., 2013). Moreover, gender patterns seem to help children learn new nouns through adjectives (Arias Trejo \& Alva, 2012).

Although processing studies have already shown early gender comprehension, further research is needed to explore other aspects of grammatical gender processing; for example, whether children are capable of learning new words based on article-noun distributional co-occurrences. Another aspect of interest is the exact tim- 
ing when children start processing transparent and opaque nouns differently, as reported for adults, or when they become sensitive to the transparency and opaqueness of the noun ending.

Another interesting research line is to explore the mechanisms through which young children process common gender nouns, such as astronauta 'astronaut' or cantante 'singer'. These nouns are frequently used in a so-called "masculine generic" form. In a recent study by Gygax, Schoenhals, Lévy, Luethold and Gabriel (2019), French children (3-5 years old) participated in a trial to test whether they were affected by masculine generic forms. In an experimental task, children were presented with two pairs of pictures (one pair including two boys, another pair including one boy and one girl) and were asked to look at, for example, "nurses". The authors then monitored where the gaze was directed. The results suggest that 3-5-year-old French children have already acquired a masculine generic form for nouns that are stereotypically associated with male professions, as children tended to gaze more frequently at boy-boy pairs of pictures. When a profession was stereotypically associated with females, children showed gaze preference to boy-girl pairs. Since both French and Spanish are Romance languages, a similar effect can be expected in Spanish-speaking children.

In summary, the present article reviewed studies on early gender processing by Spanish-speaking children. Processing studies are highly relevant for language acquisition research, as they enable to explore comprehension before production emerges.

\section{References}

Alarcón, Irma (2006). The second language acquisition of Spanish gender agreement: The effects of linguistic variables on accuracy. Munich: Lincom Europa.

Alarcón, Irma (2009). The processing of gender agreement in L1 and L2 Spanish: Evidence from reaction time data. Hispania, 92(4), 814-828. 
Alarcón, Irma (2011). Spanish grammatical gender under complete and incomplete acquisition: Early and late bilinguals' linguistic behavior within the noun phrase. Bilingualism: Language and Cognition, 14(3), 332-350. 10.1017/S1366728910000222.

Alencar de Resende, Natália Carolina; Mota, Mailce Borges, \& Seuren, Pieter. (2018). The processing of grammatical gender agreement in Brazilian Portuguese: ERP evidence in favor of a single route. Journal of Psycholinguistic Research, 48, 181-198. 10.1007/s10936-018-9598-z

Anderson, Raquel T., \& Lockowitz, Alison (2009). How do children ascribe gender to nouns? A study of Spanish-speaking children with and without specific language impairment. Clinical Linguistics \& Phonetics, 23(7), 489-506.

Anderson, Raquel T., \& Souto, Sofía M. (2005). The use of articles by monolingual Puerto Rican Spanish-speaking children with specific language impairment. Applied Psycholinguistics, 26(4), 621-647.

Arias Trejo, Natalia, \& Alva Canto, Elda Alicia (2012). Early Spanish grammatical gender

bootstrapping: Leaning nouns through adjectives. Developmental Psychology, 1-7. 10.1037/a0029621

Arias Trejo, Natalia; Falcón, Alberto, \& Alva Canto, Elda Alicia (2013). The gender puzzle:

Toddlers' use of articles to access noun information. Psicológica, $34,1-23$.

Barreña, Andoni (1997). Desarrollo diferenciado de sistemas gramaticales en un niño vasco-español bilingüe. In Ana T. Pérez-Leroux \& W. R. Glass (Eds.), Contemporary perspectives on the acquisition of Spanish. Vol. I: Developing grammars (pp. 55-74). Somerville: Cascadilla. Bates, Elizabeth; Devescovi, Antonella; Hernández, Arturo, \& Pizzamiglio, Luigi (1996). Gender priming in Italian. Perception \& Psychophysics, 58(7), 992-1004. 10.3758/BF03206827

Bates, Elizabeth; Devescovi, Antonella; Pizzamiglio, Luigi; D’amico, Simona, \& Hernández, Arturo (1995). Gender and lexical access in Italian. Perception \& Psychophisics, 57(6), 847-862. 10.3758/BF03206800

Bedore, Lisa M., \& Leonard, Laurence B. (2001). Grammatical morphology deficits in Spanish-speaking children with specific language impairment. Journal of Speech, Language, and Hearing Research, 44(4), 905-924. 
Bedore, Lisa M., \& Leonard, Laurence B. (2005). Verb inflections and noun phrase morphology in the spontaneous speech of Spanish-speaking children with specific language impairment. Applied Psycholinguistics, 26(2), 195-225.

Bosch, Laura, \& Serra, Miquel (1997). Grammatical morphology deficits of Spanish-speaking children with specific language impairment. In Anne Baker, Mieke Beers, Gerald Bol, Jan de Jong \& Geertje Leemans (Eds.), Child language disorders in a cross-linguistic perspective. Proceeding of the Fourth Symposium of the European Group on Child Language Disorders (33-45). Amsterdam: Amsterdam Series in Child Language Development.

Boloh, Yves, \& Ibernon, Laure (2010). Gender attribution and gender agreement in 4-to 10-year-old French children. Cognitive Development, 25(1), 1-25. https://doi.org/10.1016/j.cogdev.2009.09.011

Bull, William (1965). Spanish for teachers: Applied linguistics. New York: Ronald. Caffarra, Sendy, \& Barber, Horacio A. (2015). Does the ending matter? The role of gender-to-ending consistency in sentence reading. Brain Research, 1605, 83-92. 10.1016/j.brainres.2015.02.018

Caffarra, Sendy; Janssen, Niels, \& Barber, Horacio A. (2014). Two sides of gender: ERP evidence for the presence of two routes during gender agreement processing. Neuropsycologia, 63, 124-134. 10.1016/j.neuropsycho logia.2014.08.016

Caffarra, Sendy; Siyanova-Chanturia, Anna; Pesciarelli, Francesca; Vespignani, Francesco, \& Cacciari, Cristina (2015). Is the noun ending a cue to grammatical gender processing? An ERP study on sentences in Italian. Psychophysiology, 52(8), 1019-1030. 10.1111/psyp.12429

Clark, Eve V. (1985). The acquisition of Romance, with special reference to French. In Dan Isaac Slobin (Ed.), The crosslinguistic study of language acquisition. Vol 1. The data (pp. 688-782). Hillsdale: Lawrence Erlbaum.

Clark, Eve V. (1993). The lexicon in acquisition. Cambridge: Cambridge University Press.

Clark, Eve V., \& Hecht, Barbara Frant (1983). Comprehension, production, and language acquisition. Annual Review of Psychology, 34, 325-349.

Corbett, Greville G. (1991). Gender. Cambridge: Cambridge University Press. 
Eddington, David, \& Hualde, José Ignacio (2008). El abundante agua fría: Hermaphroditic Spanish nouns. Studies in Hispanic Lusophone Linguistics, 1(1), 5-31. 10.1515/shll-2008-1004

Gollan, Tamar H., \& Frost, Ram (2001). Two routes to grammatical gender: Evidence from Hebrew. Journal of Psycholinguistic Research, 30(6), 627-651. 10.1023/A:1014235223566

Grüter, Theres; Lew-Williams, Casey, \& Fernald, Anne (2012). Grammatical gender in L2:

A production or a real-time processing problem? Second Language Research, 28(2), 191-215. 10.1177/0267658312437990

Gygax, Pascal Mark; Schoenhals, Lucie; Lévy, Arik; Luethold, Partick, \& Gabriel, Ute (2019). Exploring the onset of a male-biased interpretation of masculine generics among French speaking kindergarten children. Frontiers in Psychology, 10. 10.3389/fpsyg.2019.01225

Harris, James W. (1991). The exponence of gender in Spanish. Linguistic Inquiry, 22(1), 27-62.

Hernández-Pina, Fuensanta (1984). Teorías psicosociolingüísticas y su aplicación a la adquisición del español como lengua materna. Madrid: Siglo XXI.

Huttenlocher, Janellen (1974). The origins of language comprehension. In Robert L. Solso (Ed.), Theories in cognitive psychology: The Loyola symposium (pp. 331-68). Potomac: Lawrence Erlbaum.

Jackson Maldonado, Donna, \& Maldonado, Ricardo (2017). Grammaticality differences between Spanish-speaking children with specific language impairment and their typically developing peers. International Journal of Language \& Communication Disorders, 52(6), 750-765.

Jacobson, Peggy F., \& Schwartz, Richard G. (2002). Morphology in incipient bilingual Spanish-speaking preschool children with specific language impairment. Applied Psycholinguistics, 23(1), 23-41.

Karmiloff-Smith, Annette (1979). A functional approach to child language. A study of determiners and reference. Cambridge: Cambridge University Press.

Leonard, Laurence B. (2014). Children with specific language impairment. Cambridge: MIT Press.

Levelt, Willem J. M.; Roelofs, Ardi, \& Meyer, Antje S. (1999). A theory of lexical access in speech production. Behavioural and Brain Sciences, 22(1), 1-38. 
Lew-Williams, Casey, \& Fernald, Anne (2007). Young children learning Spanish make rapid use of grammatical gender in spoken word recognition. Psychological Science, 18(3), 193-198. 10.1111/j.1467-9280.2007.01871.x Lew-Williams, Casey, \& Fernald, Anne (2010). Real-time processing of gender-marked articles by native and non-native Spanish speakers. Journal of Memory and Language, 63, 447-464. 10.1016/j.jml.2010.07.003

López Ornat, Susana; Fernández, Almudena; Gallo Valdivieso, María del Pilar, \& Mariscal Altares, Sonia (1994). La adquisición de la lengua española. Madrid: Siglo XXI. Martínez Nieto, Lourdes (2018). Spanish grammatical gender knowledge in young heritage speakers (unpublished doctoral thesis). Arizona State University, Arizona.

Miozzo, Michele, \& Caramazza, Alfonso (1997). Retrieval of lexical-syntactic features in tip-of-the tongue states. Journal of Experimental Psychology: Leaning, Memory, and Cognition, 23(6), 1410-1423.

Montrul, Silvina; Davidson, Justin; De la Fuente, Israel, \& Foote, Rebecca (2014). Early language experience facilitates the processing of gender agreement in Spanish heritage speakers. Bilingualism: Language and Cognition, 17(1), 118-138.

Montrul, Silvina, Foote, Rebecca, \& Perpiñán, Silvia (2008). Gender agreement in adult second language learners and Spanish heritage speakers: The effects of age and context of acquisition. Language Learning, 58(3), $503-553$.

Ogneva, Anastasiia (2020). Gender agreement hierarchy in common gender and epicene nouns in European Spanish. Borealis: An International Journal of Hispanic Linguistics, 9(1), 279-292. http://dx.doi. org/10.7557/1.9.1.4839

Ogneva, Anastasiia (2023). A review on grammatical gender acquisition in monolingual Spanish-speaking children. Onomázein, 59. 10.7764/ onomazein.59.03

Pérez Pereira, Miguel (1991). The acquisition of gender: what Spanish children tell us? Journal of Child Language, 18(3), 571-590. 10.1017/ S0305000900011259

Pérez-Tattam, Rocío; Ezeizabarrena, Maria José; Stadthagen-González, Hans, \& Mueller Gathercole, Virginia C. (2019). Gender assignment to Spanish pseudowords by mono- 
lingual and Basque-Spanish bilingual children. Languages, 4(3), 1-18. 10.3390/languages 4030058

Rescorla, Leslie A. (1980). Overextension in early language development. Journal of Child Language, 7(2), 321-335.

Sagarra, Nuria, \& Herschensohn, Julia (2011). Proficiency and animacy effects on L2 gender agreement processes during comprehension. Language Learning, 61(1), 80-116. https://doi.org/10.1111/j.14679922.2010.00588.x

Smolik, Filip, \& Bláhová, Veronika (2019). Czech 23-month-olds use gender agreement to anticipate upcoming nouns. Journal of Experimental Child Psychology, 178, 251-265. 10.1016/j.jecp.2018.10.004

Van Heugten, Marieke, \& Johnson, Elizabeth K. (2011). Gender-marked determiners help Dutch learners' word recognition when gender information itself does not. Journal of Child Language, 38(1), 87-100. 10.1017/ S0305000909990146

Van Heugten, Marieke, \& Shi, Rushen (2009). French-learning toddlers use gender information on determiners during word recognition. Developmental Science, 12(3), 419-425. 10.1111/j.1467-7687.2008.00788.x

White, Lidya; Valenzuela, Elena; Kozlowska-MacGregor, Martyna, \& Leung Yan-Kit (2004). Gender and number agreement in nonnative Spanish. Applied Psycholinguistics, 25(1), 105-133. 
